\title{
Effect of Hemp'S Soluble Components on the Physical Properties of Hemp Concrete
}

\author{
Rosanne Walker ${ }^{1} \&$ Sara Pavía ${ }^{1}$ \\ ${ }^{1}$ Dept of Civil Engineering, Trinity College, Dublin 2, Ireland \\ Correspondence: Sara Pavía, Dept of Civil Engineering, Trinity College, Dublin 2, Ireland. Tel: 353-1896-2516. \\ E-mail: pavias@tcd.ie
}

Received: November 21, 2013

Accepted: February 28, 2014 Online Published: June 13, 2014

doi:10.5539/jmsr.v3n3p12

URL: http://dx.doi.org/10.5539/jmsr.v3n3p12

\begin{abstract}
Lime hemp concrete is a sustainable building material made with hemp shiv and lime. In this research, pozzolans are added to the lime binder. Hemp shiv contains water soluble constituents including pectic polysaccharides which can dissolve in the mixing water. Sugars and pectins are known to retard clinker hydration in portland cement. This research studies whether the hemp soluble components impact lime-pozzolan paste reactions thus affecting the properties of hemp concrete with lime-pozzolan binder. Physical tests and microstructural analyses were undertaken to determine how the water soluble hemp constituents influence the hydration reactions responsible for setting and hardening of lime-pozzolan pastes. The effect of hemp particles on a lime-pozzolan binder was also investigated using microstructural analysis.

Physical testing evidenced that the hemp's soluble constituents do not alter ultimate strength however, they delay pozzolanic reaction retarding setting and early strength development. The microstructural analysis of lime-pozzolan pastes agreed with the above, evidencing that the hemp delays the formation of hydrates, in particular calcium silica hydrates. The halt of the pozzolanic reaction by the hemp particles was clear at the hemp interface, where few hydrates were evident. This suggests that the properties of the hemp particles including their high suction (which removes water at the interface) and their high porosity (which assists $\mathrm{CO}_{2}$ diffusion) contribute to the halt of the pozzolanic reaction.
\end{abstract}

Keywords: lime-hemp concrete, pectin, pozzolanic reaction, hydration, setting, strength

\section{Introduction}

Lime hemp concrete is a sustainable, carbon negative building material that can replace high embodied energy materials in certain applications thus making construction more sustainable. Lime hemp composites have been used in France since the 1990s and are gaining popularity in Europe. They are made with hemp shiv, which is the woody interior of the hemp stalk, and a lime-based binder. Commercial binders currently available and binders designed on site by building practitioners typically include hydraulic lime, portland cement (PC) and additions. The purpose of the hydraulic lime and PC is to improve early age properties such as setting and strength development. This paper is part of a research programme which aims at formulating a binder using calcium lime and pozzolans. It is intended that the pozzolans will eliminate the need for hydraulic lime and PC so that the material can have a lower environmental impact.

Pozzolans are materials with an amorphous siliceous or siliceous and aluminous content that react with portlandite $\left(\mathrm{CH}=\mathrm{Ca}(\mathrm{OH})_{2}\right)$ in the presence of water to form hydrates (similar to cement hydration) thereby accelerating the slow hardening (carbonation) of calcium limes by imparting a hydraulic set. They have been used to enhance the properties of composites since antiquity. Previous research by the authors indicated two suitable pozzolans for use in lime hemp composites: Ground Granulated Blastfurnace Slag (GGBS) and metakaolin; on account of their fast setting and high reactivity (Walker \& Pavía, 2010; Walker \& Pavía, 2011). In this paper, Rice Husk Ash (RHA) was also included in several tests to study the effect of the pectins on a fully siliceous pozzolan.

\subsection{Effect of Organic Compounds on Material Properties}

The amount and type of hydrates produced upon binder hydration, and the time at which they appear, impact the physical properties of cement and lime composites, including setting and early strength development. Sugars and 
pectins are known to retard hydration in cement (Young, 1972; Ramachandran, Feldman, \& Beaudoin, 1981). Hemp comprises of cellulose, hemicelluloses, lignin and pectin, and the percentage of each component is dependent on a number of variables such as growing conditions, maturity and decortification. Some of these are water soluble (including pectin). They can dissolve in the mixing water and have been reported to delay the set of gypsum binders by trapping calcium ions, thus resulting in a lack of calcium available to form calcium silicate hydrates (Dalmay et al., 2010). The hemp pectins are partly present as methyl esters (Figure 1). In an alkaline environment, their ester groups saponify and react with the calcium ions of lime (CH-portlandite) (Zsivanovits, MacDougall, Smith, \& Ring, 2004; Renard \& Thibault, 1996; Fang et al., 2008; Sedan et al., 2007; Kavasa, Olgunb, Erdoganb, \& Oncec, 2007).

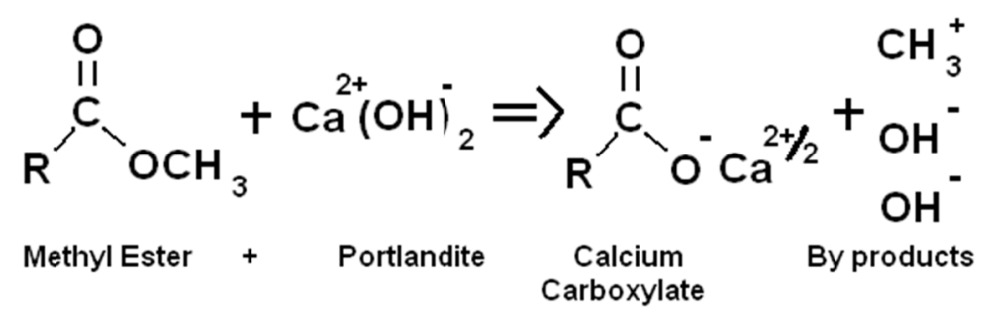

Figure 1. Summary of behaviour of water soluble pectin present as a methyl ester in a lime-rich media

Research to date has focused on the influence of hemp fibre in PC and gypsum binders, however, this paper investigates the influence of hemp shiv on the lime and lime- pozzolan reactions that govern the early properties of lime hemp concrete.

\subsection{Relationships Between Hydration, Setting and Hardening}

As aforementioned, the amount and type of hydrates formed in binder reactions and the time at which they appear impact the physical properties of cement and lime composites, including setting and strength development. For example in PC, silicate hydrates are stronger than aluminates (Bogue \& Lerch, 1934; Beaudoin \& Ramachandran, 1992) thus they are the main contributors to strength since early age (1 -10 days). At 28 days, $\mathrm{C}_{2} \mathrm{~S}$ has a compressive strength of c.5MPa while $\mathrm{C}_{3} \mathrm{~A}$ strength is close to zero (Beaudoin \& Ramachandran 1992). Aluminates, despite contributing little to strength, are responsible for the early set of the paste.

The hydration of the lime- pozzolan mixes in this research differs from PC hydration but produces similar compounds since the overall chemical composition of the two systems is similar. Differences are minor and generally affect the amount rather than the nature of the hydrate phases formed (Massazza, 2007) which include calcium silicate hydrates (CSH) and calcium silica aluminate hydrates (CSAH).

In general, the acceleration of hydration contributes to strength development. The acceleration of the pozzolanic reaction positively affects strength development, and the rate of strength increase depends on the type of pozzolan (amount of lime that it combines) and the type and microstructure of the hydration products formed (Massazza, 2007). Due to the slightly different chemical composition of the pozzolans investigated (clinker-bearing GGBS; alumina-rich metakaolin and silica-rich RHA), hydration will generate similar hydrates, however in different quantities and at different times, during setting and early strength development.

In the GGBS paste, clinker hydration occurs first, and this is followed by pozzolanic reaction between the pozzolan's active silica/alumina and lime $(\mathrm{CH})$. Therefore, setting is mainly attributed to the formation of CSH upon clinker hydration. The GGBS investigated contains no $\mathrm{C}_{3} \mathrm{~A}$ clinkers however, its alumina content is $13.85 \%$ therefore, aluminates formed in pozzolanic reactions might contribute to setting.

In the RHA paste, a pozzolanic reaction occurs between the RHA's amorphous silica and lime to form CSH. RHA contains very little alumina ( $1.93 \%$ vs 45.26 in metakaolin) therefore, no significant aluminates will be found upon hydration and setting and strength development will be due to the formation of CSH.

At ambient temperature, the products of hydration of lime- metakaolin pastes are mainly CSH and CSAH (gehlenite $-\mathrm{C}_{2} \mathrm{ASH}_{8^{-}}$and $\mathrm{C}_{4} \mathrm{AH}_{13}$ ) (Murat, 1983; de Silva \& Glasser, 1993; He, Makovicky, \& Osbæck, 1994; Donchev, Nivov, Doykov, Petrova, \& Dimova, 2010). There is no definite sequence of formation of pozzolanic hydration products due to numerous variables. However, Rojas and Cabrera (2002) report that CSH forms first followed by $\mathrm{C}_{2} \mathrm{ASH}_{8}$ and later $\mathrm{C}_{4} \mathrm{AH}_{13}$ which progressively increases over time. According to this, the initial set 
of the paste should be due to the formation of $\mathrm{CSH}$. A previous study which compared reactivity of a number of pozzolans found that pozzolans with the highest $\mathrm{Al}_{2} \mathrm{O}_{3}$ content set the fastest (Walker \& Pavía, 2010; Walker \& Pavía, 2011), therefore, it is likely that aluminates also contribute to setting.

\section{Materials and Methods}

\subsection{Materials}

A hydrated commercial lime (CL90s) complying with EN 459-1 was used. As aforementioned, two pozzolans, metakaolin and GGBS, were identified as having potential for use in the lime hemp composite on account of their fast setting times and high reactivity (Walker \& Pavía, 2010; Walker \& Pavía, 2011). The programme of research concentrates on these two pozzolans however RHA was included in several tests to study the effect of the pectins on a fully siliceous pozzolan. The pozzolan composition, rate of amorphousness and surface area are included in Table 1.

The chemical composition was determined by XRF using a Quant'X EDX Spectrometer and UniQuant analysis package. The mineralogy and rate of amorphousness were analysed by X-Ray diffraction (XRD), using a Phillips PW1720 XRD with a PW1050/80 goniometer and a PW3313/20 Cu k-alpha anode tube at $40 \mathrm{kV}$ and $20 \mathrm{~mA}$. The specific surface area was measured using a Quantachrome Nova 4200e and the BET method, a model isotherm based on adsorption of gas on a surface. Industrial hemp shiv was supplied by La Chanvrière De L'aube in central France.

Table 1. Properties of the pozzolan

\begin{tabular}{|c|c|c|c|c|c|c|c|c|c|c|}
\hline Pozzolan & $\mathrm{SiO}_{2}$ & $\mathrm{Al}_{2} \mathrm{O}_{3}$ & $\mathrm{CaO}$ & $\mathrm{Fe}_{2} \mathrm{O}_{3}$ & $\mathrm{SO}_{3}$ & $\mathrm{~K}_{2} \mathrm{O}$ & $\mathrm{MgO}$ & $\begin{array}{c}\text { Rate of } \\
\text { Amorph-ousness }\end{array}$ & $\begin{array}{c}\text { Surface } \\
\text { area } \mathrm{m}^{2} / \mathrm{g}\end{array}$ & Mineral composition \\
\hline GGBS & 34.1 & 13.9 & 39.3 & 0.4 & 2.4 & 0.3 & 8.6 & Totally & 2.65 & no crystalline fraction \\
\hline Metakaolin & 51.4 & 45.3 & - & 0.5 & - & 2.1 & 0.6 & Mostly & 18.30 & $\begin{array}{l}\text { quartz, tohdite, } \\
\text { aluminum oxide, } \\
\text { wollastonite and } \\
\text { paragonite. }\end{array}$ \\
\hline RHA & 93.8 & 1.9 & 0.7 & 0.3 & - & 1.4 & 0.5 & Mostly & 13.70 & quartz and crystobalite \\
\hline
\end{tabular}

As shown in Table 1, the chemical and mineral composition, rate of amorphouseness and surface area of pozzolans (Walker \& Pavía, 2010; Walker \& Pavía, 2011).

\subsection{Setting Time}

It is not possible to determine the setting time of composites such as hemp concrete using the Vicat test as the organic aggregate impedes needle penetration and absorbs water; hastening the drying of the paste and giving inaccurate results. Therefore, the hemp aggregate was replaced by hemp water; and the effect of hemp on setting determined by comparing the Vicat test results of pastes made with water and hemp water. Mixing was in accordance with EN 459-2 except for the addition of the pozzolan (added after 1 minute and the mixing stopped for 30 seconds).

The hemp water was prepared by soaking the shiv for 45 minutes so that it releases its water soluble constituents including pectins. The concentration of soluble hemp compounds in the mixing water present in the lime hemp concrete during curing was not established. Longer soaking times would yield a higher concentration of soluble compounds, however it was felt that long soaking times in a water excess were not representative of the actual conditions in hemp concrete, thus soaking the shiv for 45 minutes was deemed an adequate solution. The influence of varying amounts of soluble hemp compounds on setting was measured by varying the hemp water content $(0,25,50$ and $100 \%)$.

\subsection{Water Content for Setting}

Consistency in the water content is of paramount importance as it affects the kinetics of the binder reactions and the final properties of the material: a small water increase significantly delays setting of lime-pozzolan pastes (Walker \& Pavía, 2010). A standard consistency for the lime-pozzolan pastes was achieved by adding the amount of water necessary to produce a paste with a $165 \mathrm{~mm}$ initial flow diameter. The water required in order to produce such paste was measured according to EN 459-2. The quantity of water required by different 
pozzolans to produce a paste of the same standard consistency (necessary for the Vicat test) varies: GGBS has a much lower water demand than lime while, in contrast, lime and metakaolin have a similar water demand (Walker \& Pavía, 2011). For the lime- GGBS pastes, the binder: water ratio of 1:0.69 and 1:0.64 for the 30\% and $37.5 \%$ (Figure 2) GGBS content respectively. As hydrated lime and metakaolin have a similar water demand, the water content of the lime- metakaolin pastes was determined at $37.5 \%$ pozzolan content and fixed at a lime+pozzolan:water ratio of 1:0.93 (by weight) for both pozzolan contents.

\subsection{Compressive and Flexural Strength}

Strength was measured at $30 \%$ pozzolan content with the water content adjusted to produce a $165 \mathrm{~mm}$ initial flow diameter. The prisms were demoulded after 1 day and stored in a curing room at $20^{\circ} \mathrm{C} \pm 3^{\circ} \mathrm{C}$ and $\mathrm{RH}$ $60 \% \pm 10 \%$. The unconfined compressive strength was measured according to EN196-1 and EN 459-2 at 28 days.

Flexural strength tests were conducted according to EN196-1 and EN 459-2 using the center-point loading method. Here, the prisms were placed on fixed supports with the longitudinal axis normal to the applied load. After breaking the prism, the following equation was used to determine the flexural strength:

$$
\mathrm{R}_{\mathrm{f}}=\left(1.5 \times \mathrm{F}_{\mathrm{f}} \times 1\right) / \mathrm{b}^{3}
$$

$\mathrm{R}_{\mathrm{f}} \quad$ flexural strength $\left(\mathrm{N} / \mathrm{mm}^{2}\right)$

$\mathrm{F}_{\mathrm{f}} \quad$ load applied to the middle of the prism at fracture $(\mathrm{N})$

b side of the square section of the prism (mm)

1 distance between the supports $(\mathrm{mm})$

The values reported are the mean of 6 compressive and 3 flexural strength tests.

\subsection{Analysis of Hydration Products With Scanning Electron Microscopy (SEM)}

SEM and XRD were used to determine whether water soluble constituents of hemp were responsible for a difference in the nature and/or amount of hydrates. The microstructure of the binder and the formation of hydrates were investigated using a Tescan MIRA Field Emission SEM. The samples were fractured and covered with a gold coating in an 'Emscope SC500' plasma coating unit. Lime- pozzolan pastes (30\% pozzolan by weight) were investigated at 1, 3, 7 and 28 days. Pastes with $2 \%$ hemp content (untreated and washed hemp in which the hemp was immersed in water for 24 hours and then dried prior to mixing) were investigated at 28 days. 15 random areas were analyzed in each sample.

XRD was undertaken on the lime- pozzolan pastes, at different ages up to 6 months, using a Phillips PW1720 XRD with a PW1050/80 goniometer and a PW3313/20 Cu k-alpha anode tube at $40 \mathrm{kV}$ and $20 \mathrm{~mA}$.

\subsection{Testing Regime}

The testing regime of the different pastes is as set out in Table 2.

Table 2. Matrix of testing

\begin{tabular}{|c|c|c|c|c|c|}
\hline Property & Test & Pozzolan & $\begin{array}{l}\text { Pozzolan } \\
\text { Content }\end{array}$ & Additions & Figure \\
\hline Setting & Vicat Test & $\begin{array}{l}\text { Lime, GGBS, } \\
\text { metakaolin, RHA }\end{array}$ & $37 \%$ & Hemp water & $\begin{array}{l}\text { Section } 3.1, \\
\text { Figure } 2\end{array}$ \\
\hline Setting & Vicat Test & GGBS, metakaolin & $30 \%$ & $\begin{array}{l}\text { Hemp water } \\
(0-100 \%)\end{array}$ & $\begin{array}{l}\text { Section } 3.1 \text {, } \\
\text { Figure } 3\end{array}$ \\
\hline Compressive strength & $\begin{array}{l}\text { EN196-1 } \\
\text { EN459-2 }\end{array}$ & $\begin{array}{l}\text { Lime, GGBS, } \\
\text { metakaolin }\end{array}$ & $30 \%$ & Hemp water & $\begin{array}{l}\text { Section } 3.2, \\
\text { Figure } 4,5\end{array}$ \\
\hline Flexural strength & $\begin{array}{l}\text { EN196-1 } \\
\text { EN459-2 }\end{array}$ & $\begin{array}{l}\text { Lime, GGBS, } \\
\text { metakaolin }\end{array}$ & $30 \%$ & Hemp water & $\begin{array}{l}\text { Section } 3.3 \text {, } \\
\text { Figure } 6\end{array}$ \\
\hline Microstructural analysis & SEM & $\begin{array}{l}\text { GGBS, metakaolin, } \\
\text { RHA }\end{array}$ & $30 \%$ & Hemp water & $\begin{array}{l}\text { Section } 3.4, \\
\text { Figure } 7,8\end{array}$ \\
\hline Microstructural analysis & SEM & $\begin{array}{l}\text { GGBS, metakaolin, } \\
\text { RHA }\end{array}$ & $30 \%$ & Hemp particles & $\begin{array}{l}\text { Section } 3.4, \\
\text { Figure } 9,10\end{array}$ \\
\hline
\end{tabular}

As shown in Table 2, the testing undertaken in this research. 


\section{Results and Discussion}

\subsection{Effect of Water-Soluble Hemp Components on Setting Time}

The pozzolanic reaction is significantly controlled by the pozzolan's active silica and alumina content (Massazza, 2007). The pozzolans have a different composition ranging from the clinker-bearing GGBS to the alumina-rich metakaolin and the silica-rich RHA. As aforementioned, RHA was introduced in order to ascertain the effect of the hemp on an almost fully siliceous pozzolan. A 100\% calcium lime paste was included as a control sample.

The results show that hemp's soluble constituents do not alter the setting time of lime: both the lime and the lime/hemp-water pastes display a similar set, with the final set at 110 hours and a maximum deviation of 9 hours (Figure 2). This indicates that the hemp does not alter mechanical processes such as flocculation, drying and early carbonation responsible for the initial hardening of lime. In contrast, the hemp water retards the setting of lime- pozzolan pastes. RHA is retarded the most followed by GGBS and metakaolin: 39, 23 and 10 hours respectively for a setting equivalent to a depth of penetration of the Vicat needle of $25 \mathrm{~mm}$ (Figure 2). Therefore, the hemp delays pozzolanic reaction and the amount of retardation is partially determined by the chemical composition of the pozzolan.

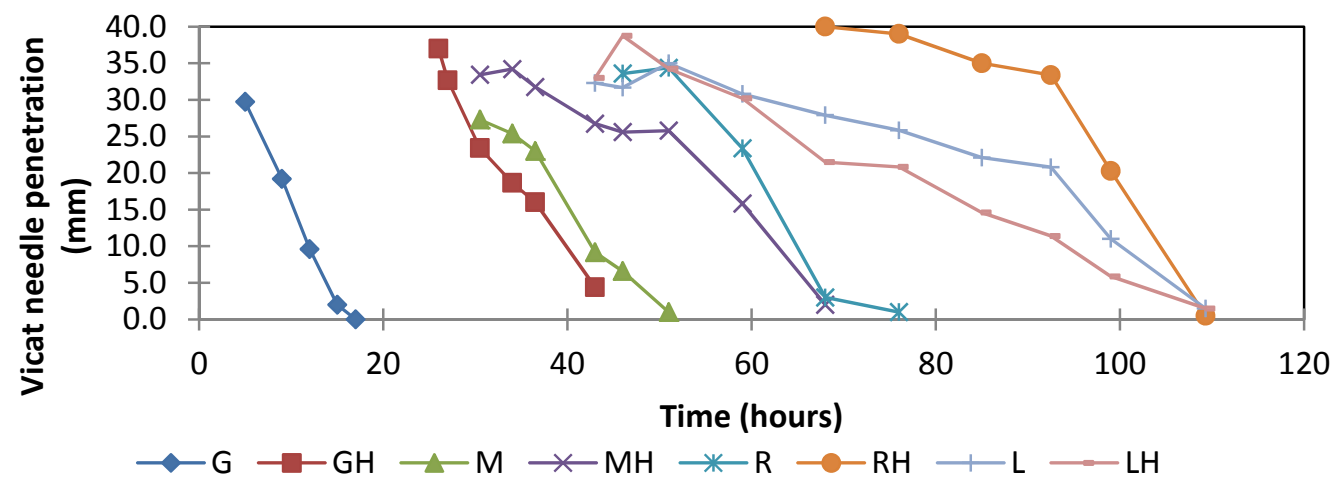

Figure 2. Setting time of lime (L) and lime- pozzolan pastes, with and without hemp water. G-GGBS; M-metakaolin; R-RHA; H-hemp water. All $37.5 \%$ pozzolan content by weight

It could be argued that the retardation of the set is due to the water soluble hemp constituents retaining water in the binder rather than delaying pozzolanic reaction. However, the samples were continuously weighed during drying, and the similar drying rates of all samples (with and without hemp water) indicate that there is no water retention triggered by the water soluble hemp constituents. Therefore the set retardation is due to the soluble hemp constituents interfering with the lime-pozzolan reactions responsible for setting.

The setting of the most siliceous pozzolan (RHA) is retarded the most; the initial set starts late (at approximately 80 hours). In contrast, the setting of the alumina-rich pozzolan paste (metakaolin) is delayed the least, despite the fact that it contains more soluble hemp compounds due to its greater water demand (section 2.3). This suggests that the hydration of silica is retarded to a greater extent than that of alumina and agrees with previous authors stating that retardation by pectins is greater for low $\mathrm{C}_{3} \mathrm{~A}$ cement (Peschard, Govin, Grosseau, Guilhot \& Guyonnet, 2004).

In order to assess the influence of increasing amounts of soluble hemp compounds on setting, the Vicat test was repeated with varying hemp water concentrations (ranging from $0 \%$ to $100 \%$ ) for the GGBS and metakaolin pozzolans. It is evident from the results (Figure 3) that increasing hemp water content increases the delay in setting. This was true in all cases except for the metakaolin paste with hemp water content over $50 \%$ and this may be due to the presence of a surplus of soluble hemp constituents on account of the higher water content in the lime- metakaolin pastes. It was also evidenced that a small amount of hemp water (25\%) significantly delays setting. 


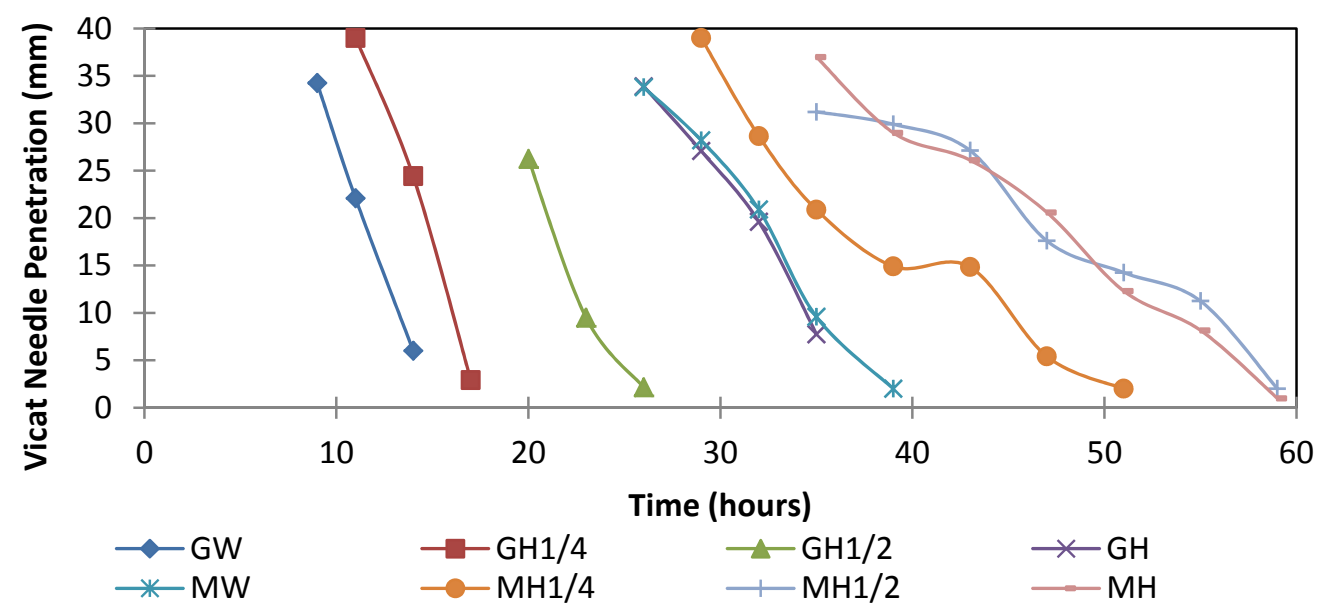

Figure 3. Influence of increasing soluble hemp compounds on the setting of lime- pozzolan pastes. G-GGBS; Mmetakaolin; $\mathrm{W}=100 \%$ water; $\mathrm{H} 1 / 4=25 \%$ hemp water and $75 \%$ water; $\mathrm{H} 1 / 2=50 \%$ hemp water; $\mathrm{H}=100 \%$ hemp water. All $30 \%$ pozzolan by weight

\subsection{Effect of Water-Soluble Hemp Components on Compressive Strength}

The impact of the soluble constituents of hemp on compressive strength was investigated in samples of $30 \%$ pozzolan content (by weight) made with water and hemp water, at 5, 7, 14 and 28 days (Figure 4). The lime samples at 5 days were still soft and compressive strength was therefore only investigated at 7, 14 and 28 days. The low coefficients of variation (Table 3 ) indicate that the results are reliable.

The results indicate that the hemp does not affect the strength development of lime pastes however, it delays the strength development of lime-pozzolan pastes (Figure 4); in particular that of the metakaolin. The pozzolanic reaction contributes to strength development and it is evident that the hemp water delays this reaction. This agrees with the setting results indicating that hemp delays pozzolanic reaction. It differs from the setting results in that metakaolin is delayed further than GGBS. However, as strength development is largely attributed to the formation of silica hydrates, it is clear that the hemp water is delaying their formation.

The magnitude of strength reduction gradually decreases over time and, at 28 days, the pozzolan pastes made with water and hemp water show similar strength. Therefore, the soluble hemp constituents undermine early strength but do not significantly affect ultimate strength.

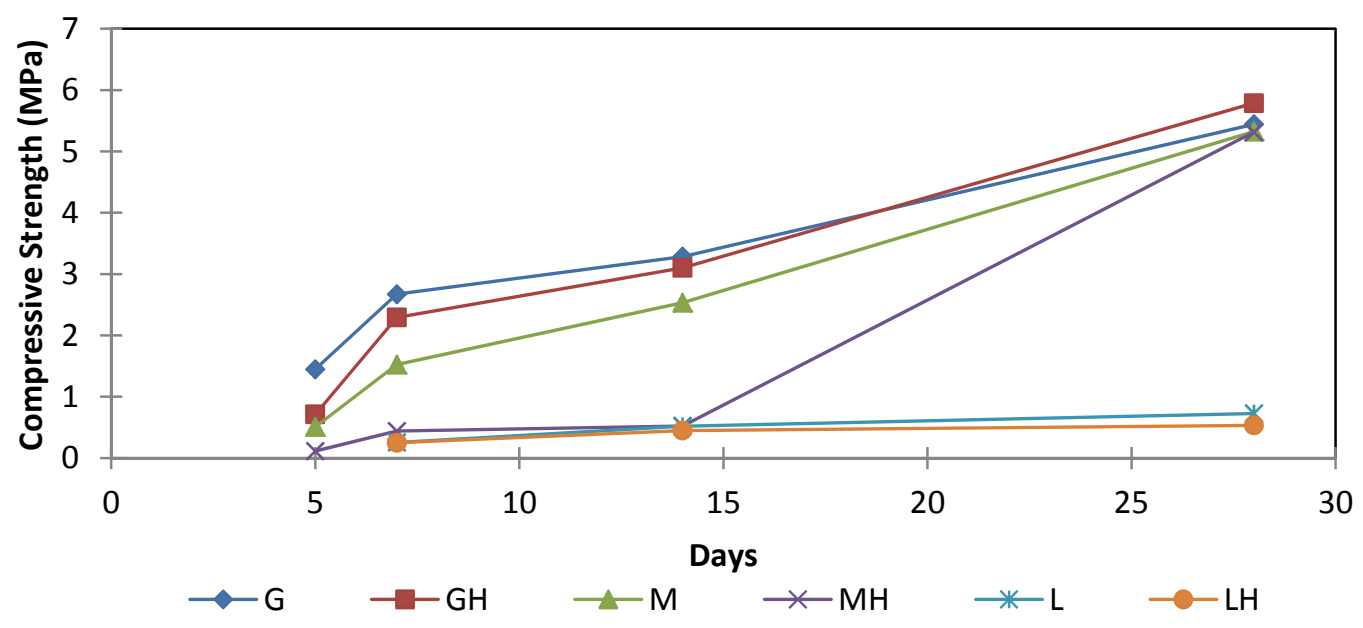

Figure 4. Influence of hemp soluble components on the compressive strength development of lime and limepozzolan pastes. G-GGBS; M-metakaolin; L-lime; H-hemp water. All 30\% pozzolan content 
Table 3. Coefficient of variation of the compressive strength results in Figure 4

\begin{tabular}{lllllll}
\hline specimen $\rightarrow$ & $\mathrm{G}$ & $\mathrm{GH}$ & $\mathrm{M}$ & $\mathrm{MH}$ & $\mathrm{L}$ & $\mathrm{LH}$ \\
\hline 5 days & 5.04 & 11.69 & 16.71 & 6.58 & & \\
7 days & 8.2 & 9.2 & 5.44 & 10.93 & 5.68 & 17.3 \\
14 days & 9.68 & 6.45 & 7.44 & 2.38 & 6.35 & 12.04 \\
\hline
\end{tabular}

In order to confirm that the soluble hemp components produce a delay in compressive strength development, the compresive strength test was repeated using aluminium sulphate as an additive. Aluminium sulphate precipitates pectins and should therefore reduce the effect of pectin on the lime-pozzolan reaction. The results (Figure 5) show that aluminium sulphate has no impact on the strength development of pastes made with water but improves the strength of pastes made with hemp water (in particular that of the metakaolin paste whose strength was lowered the most). This further confirms that the soluble hemp components (in particular pectin) cause a delay in compressive strength development.

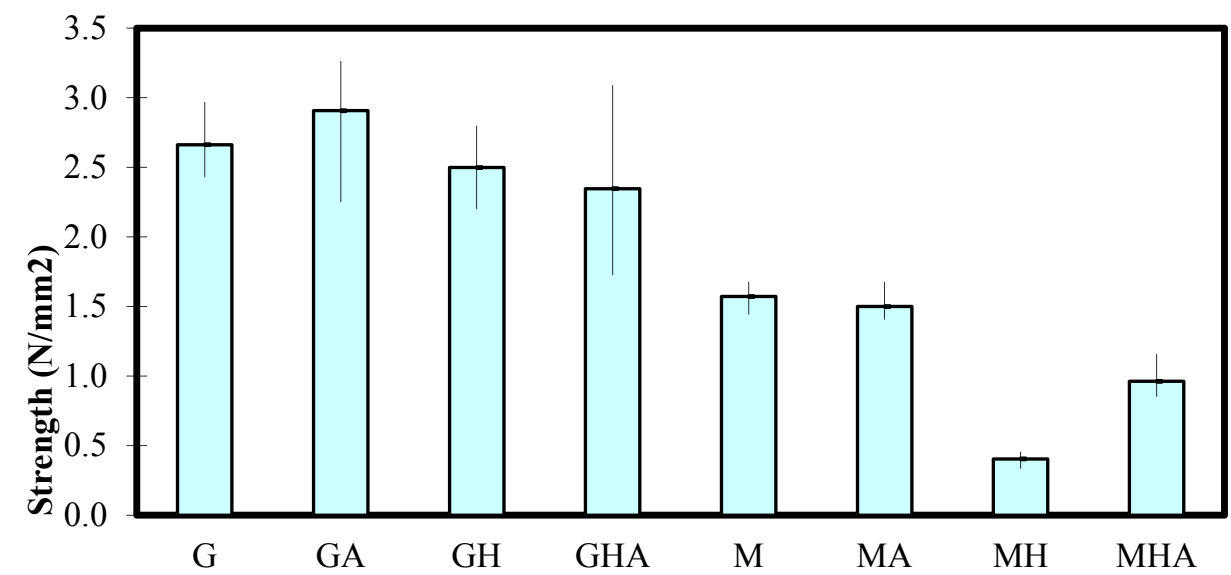

Figure 5. Influence of soluble hemp components on the early compressive strength of lime- pozzolan pastes with and without aluminium sulphate additive at 7 days. G-GGBS; M-metakaolin; L-lime; H-hemp water; A-aluminium sulphate

\subsection{Effect of Water-Soluble Hemp Components on Flexural Strength}

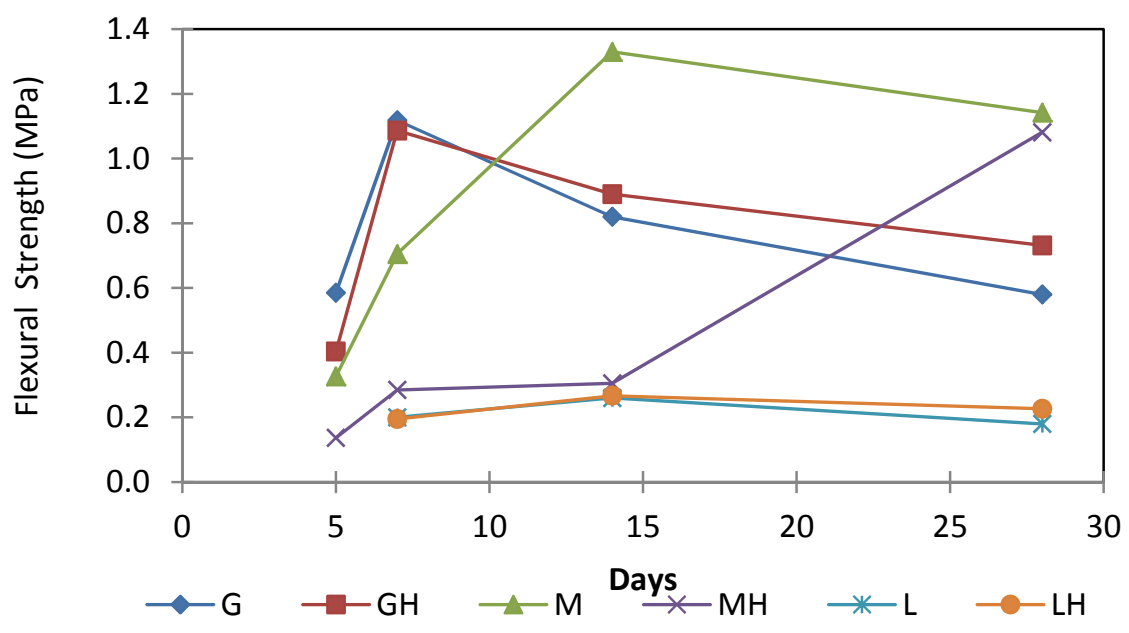

Figure 6. Flexural strength development of pastes over time. G-GGBS; M-metakaolin; L-lime; H-hemp water. All 30\% pozzolan content 
The early strength reduction caused by the hemp water is also clear in the flexural strength results. The hemp does not affect the flexural strength development of lime pastes but it delays that of the lime-pozzolan pastes (Figure 6). In addition, the early flexural strength gain of the GGBS is hardly affected whereas that of the metakaolin is lowered significantly by the presence of hemp water. These agree with compressive strength results. The low coefficients of variation (Table 4) indicate that the results are reliable.

A reduction in flexural strength of the lime-metakaolin paste made with water (M) is observed between 14 days and 28 days. This aggrees with previous authors (Donchev et al., 2010) and it is probably due to the transformation of hydration phases. The metakaolin sample made with hemp water will likely undergo a similar strength reduction over time which is not shown in the graph as a result of its delayed strength development. The lime-GGBS pastes also exhibited strength reduction and became brittle upon hardening.

Table 4. Coefficient of variation of the flexural strength results in Figure 6

\begin{tabular}{lllllll}
\hline specimen $\rightarrow$ & $\mathrm{G}$ & $\mathrm{GH}$ & $\mathrm{M}$ & $\mathrm{MH}$ & $\mathrm{L}$ & $\mathrm{LH}$ \\
\hline 5 days & 2.56 & 11.68 & 13.76 & 9.13 & & \\
7 days & 1.90 & 8.40 & 7.80 & 6.00 & 4.08 & 2.56 \\
14 days & 18.29 & 22.47 & 14.28 & 11.47 & 7.69 & 6.37 \\
\hline
\end{tabular}

\subsection{Effect of Water-Soluble Hemp Components on Hydration (XRD and SEM Results)}
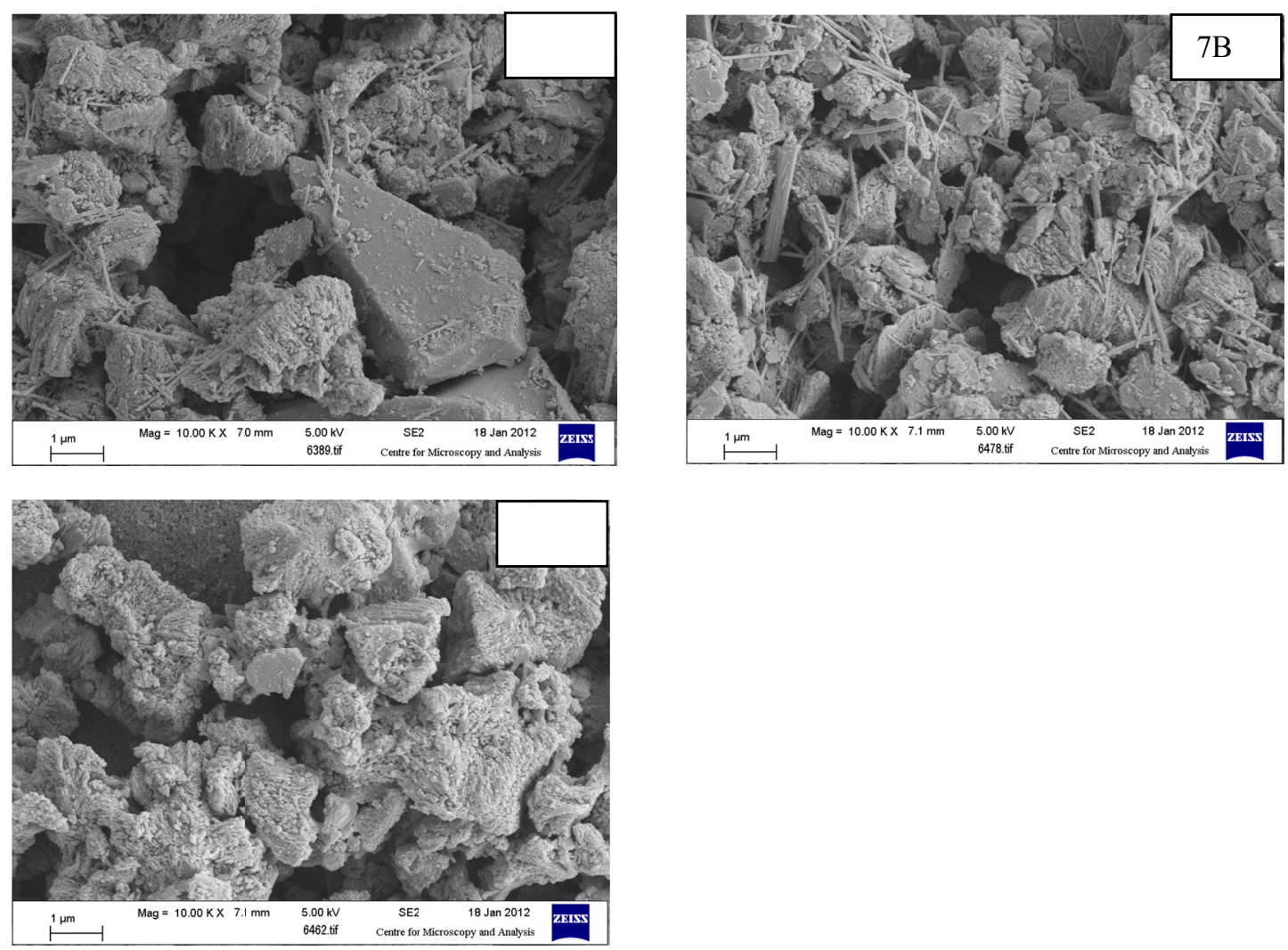

Figure 7. SEM micrographs of lime-pozzolan pastes made with hemp-water at 24 hours of curing

7A (GGBS) and 7B (metakaolin) pastes showing hydrates with needle morphology formed as a result of the pozzolanic reaction.

7C (RHA paste) showing carbonation and no pozzolanic reaction products. 
It was attempted to use XRD to determine whether the water soluble hemp constituents were responsible for a difference in the nature/ amount of hydrates formed upon pozzolanic reaction. Pastes were analysed at different ages up to 6 months however, no hydration products were detected using XRD. This was attributed to their amorphous character, low amount (XRD limit of detection is approximately 5\%) and/or concealment by other mineral peaks.

In contrast, a substantial amount of hydrates were observed in the lime-pozzolan pastes under SEM. A significant amount of hydrates were found early (at 24 hours of curing), in all lime- pozzolan pastes except in the RHA paste made with hemp-water (Figure 7). In all pastes, the morphology of the hydrates changes over time, from predominantly needle-shape at early ages to sponge and gel types at later ages. The composition of these hydrates could not be analysed due to technical limitations however, based on their morphology, the sponge and gel types as well as some of the low-crystallinity fibrous phases are likely CSH.

In the RHA pastes, there was a clear difference in the quantity of hydration products in the samples made with water and hemp water: at 1 and 3 days, there were few needle-shaped hydrates in the water pastes and none in the hemp-water pastes while at 7 days, needles and sponge type hydrates were present in the water pastes and needles begin to appear in the hemp-water pastes (Figure 8). This agrees with the setting and strength results indicating that hemp water delays hydration of silicates to form $\mathrm{CSH}$.
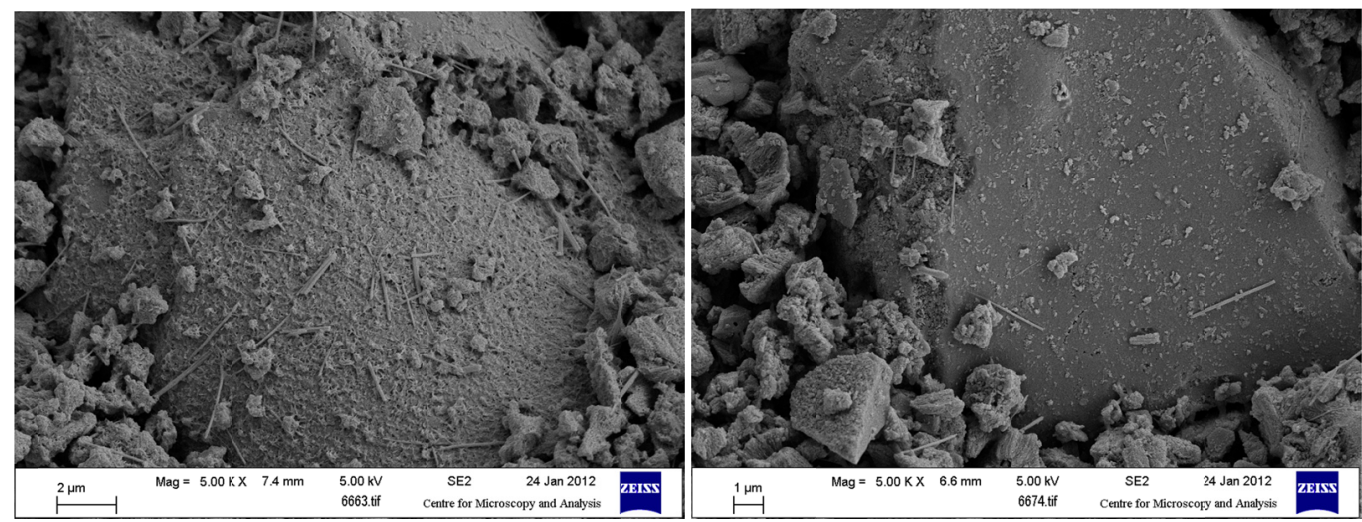

Figure 8. SEM micrographs of RHA pastes at seven days of curing showing a clear difference in the amount of hydration products. Left image: RHA particle coated with hydrates in a paste made with water. Right: RHA particle in the paste made with hemp water showing few hydrates

In the GGBS and metakaolin pastes, it was not possible to determine whether the hemp water had influenced pozzolanic reaction as there was no discernable difference in neither the type nor the amount of hydrates between the water and hemp water pastes at any stage (1,7,14, and 28 days).

SEM was also undertaken at the interface between the lime-pozzolan paste and the hemp particles. Very few hydrates were present on the hemp particles despite abundant hydrates being visible in the paste (Figure 9 and 10). Furthermore, when the hemp particles were washed to remove the water soluble constituents prior to mixing, a small amount of hydrates appeared on the particles (Figure 11) -a much smaller amount than that in the paste. This suggests that, not only the soluble hemp compounds but also the hemp particle itself contributes to the lack of hydration. An analogy can be drawn with mortar-brick interfaces, where the presence of limited hydrates has been attributed to the dewatering of the mortar as a result of high suction by the brick, reducing the water available for hydration (Reda \& Shrive, 2001 referring to Goodwin \& West, 1982). This is particularly important in lime-pozzolan binders because pozzolanic reaction starts early but is slow and therefore the presence of water is required for a long time period.

The hemp particle is a carbon dioxide reservoir as it holds air in its porous structure. It is likely that the carbonated zone on the hemp particle interface (Figures 9 and 10 - left image) is assisted by the diffusion of $\mathrm{CO}_{2}$ supplied by the particle. This would agree with Brocken and Larbi (1999) who attributed the carbonated zone at the mortar brick interface to $\mathrm{CO}_{2}$ supplied by the brick by diffusion. The prevalence of calcium carbonate may also be influenced by high mobility of calcium ions in a water environment caused by the high absorption of the shiv (as observed by Savastano and Agopyan (1999) for other vegetable fibres in a cement paste). In addition, 
the alkaline degradation of the shiv may also provide $\mathrm{CO}_{2}$ for carbonation of the portlandite, as observed by Govin, Peschard, \& Guyonnet (2006) in a cement paste with wood.
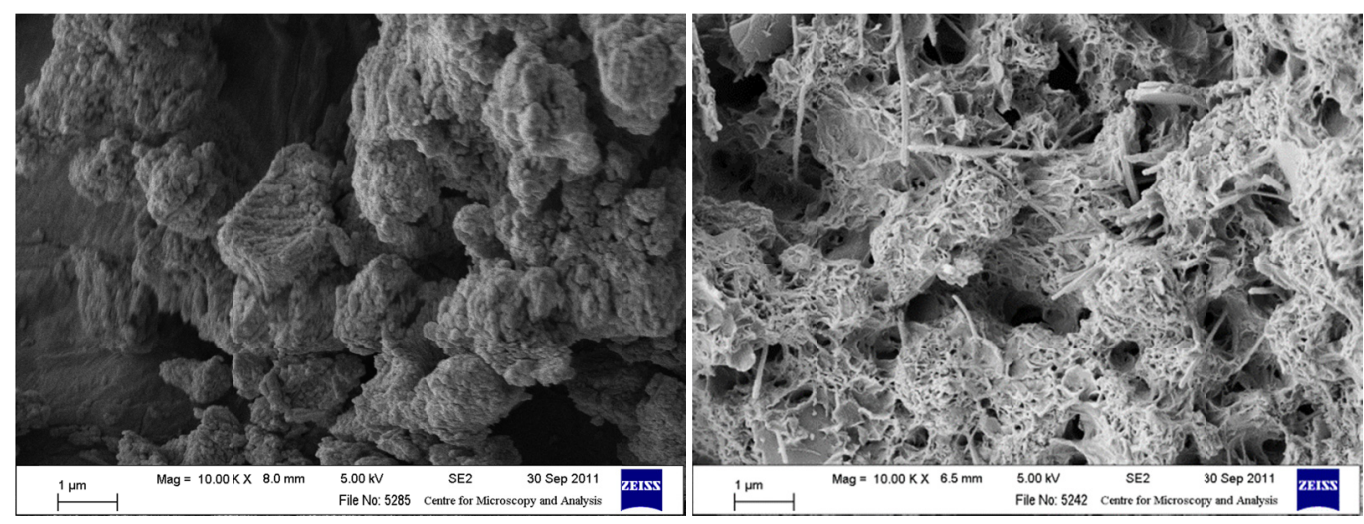

Figure 9. SEM micrographs of the lime-GGBS specimens at 28 days.

Left image: hemp interface showing carbonated lime and very few hydrates.

Right image: paste including hydrates with needle and sponge morphologies.

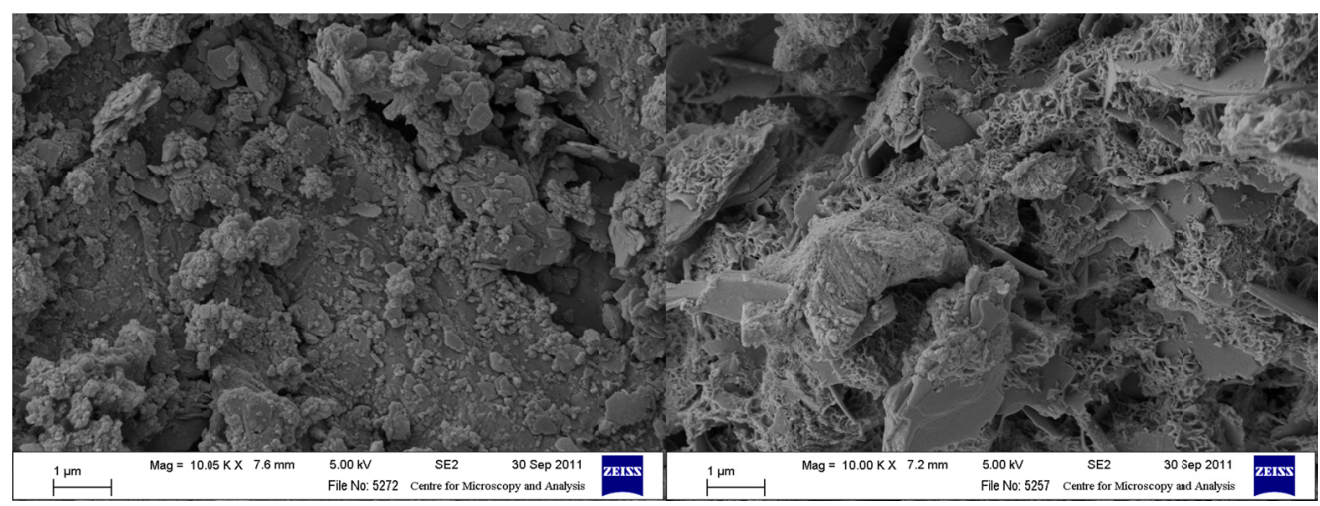

Figure 10. SEM micrographs of the lime-metakaolin specimens at 28 days

Left image: hemp interface showing carbonated lime and no hydrates.

Right image: paste including hydrates with needle and sponge morphologies.

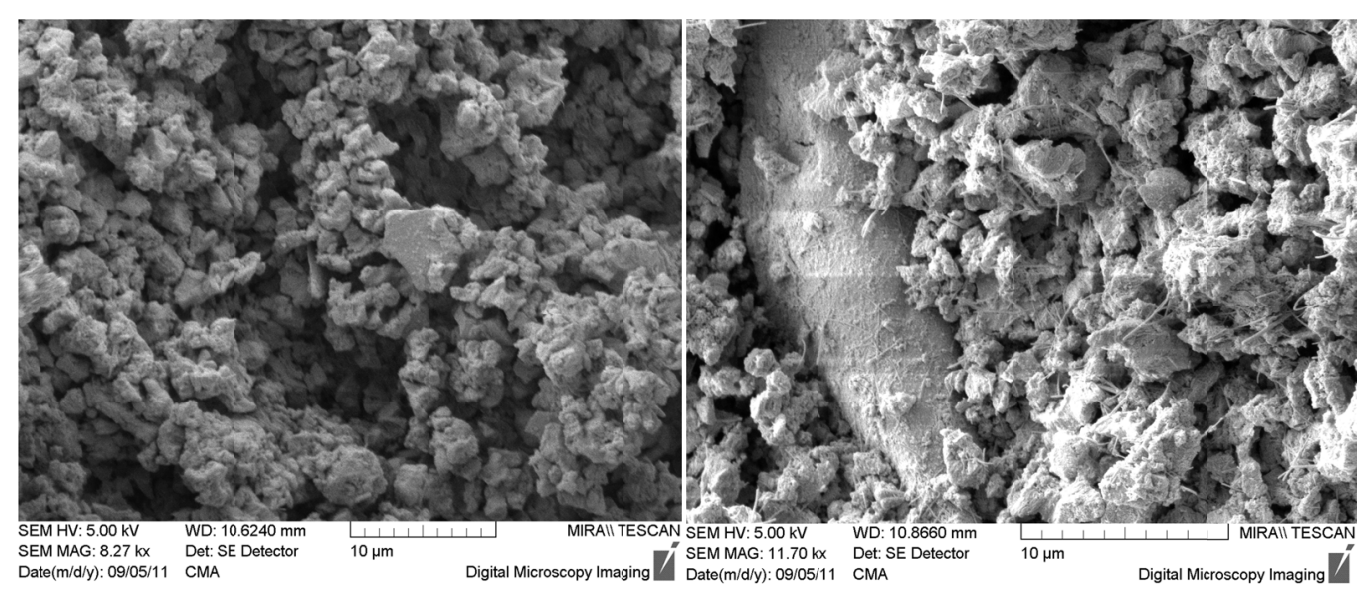

Figure 11. Morphology of the lime-GGBS specimens at the hemp particle interface at 7 days. Left image: unwashed hemp particle showing carbonated lime and no hydration. Right image: surface of a washed hemp particle with some hydrates 


\section{Conclusion}

The water-soluble hemp components delay hydration. As a result, they retard the setting and early strength development of lime-pozzolan pastes however, they do not affect their ultimate strength. In contrast, the soluble hemp compounds do not impact the setting, hardening and initial strength development of calcium lime pastes. The results also revealed that the water-soluble hemp components delay the formation of silica hydrates further than alumina hydrates.

It was noted that a small amount of hemp water significantly halts hydration. The effect of hemp water does not increase linearly with concentration; at high hemp water contents, increasing concentration has a smaller effect. This is likely on account of a surplus of active hemp components in solution.

The SEM analysis agreed with the setting and strength results indicating that hemp water delays the formation of hydrates. This was clearly evident in the lime-RHA pastes in where a delay in the formation of CSH was readily observed.

The halt of the pozzolanic reaction by the hemp particles was clear at the hemp interface, where few hydration products appeared and their quantity slightly increased when the hemp particles were washed to remove their water soluble constituents. This paper concludes that the properties of the hemp particles, including their high suction removing water at the interface and their high porosity assisting $\mathrm{CO}_{2}$ diffusion, contribute to the halt of the pozzolanic reaction.

This research also evidenced that pozzolanic reaction takes place early in lime-pozzolan pastes (significant hydrates were observed at 24 hours). An evolution in the morphology of the pozzolanic hydrates over time, from predominantly needle-shaped at very early ages ( 24 hours); into fibrous, sponge and gel-like hydrates at later stages, was determined.

\section{Acknowlegements}

The authors wish to thank the Environmental Protection Agency for funding this research. The authors also thank the Traditional Lime Company, Clogrennane Lime and Ecocem for the provision of materials and also Dr Heath Bagshaw, Mr. Neal Leddy and Mr. Colin Reid (Centre for Microscopy and Analysis) and Dr. Robbie Goodhue (Geology Department) for their help with the SEM and XRD respectively.

\section{References}

Beaudoin, J. J., \& Ramachandran, V. S. (1992). A new perspective on the hydration characteristics of cement phases. Cement and Concrete Research, 22, 689-694. http://dx.doi.org/10.1016/0008-8846(92)90021-M

Bogue, R. H., \& Lerch, W. (1934). Hydration of Portland Cement Compounds. Industrial \& Engineering Chemistry Research, 26, 837-847.

Brocken, H. J. P., \& Larbi, J. A. (1999). Composition of mortar as a function of distance to the brick-mortar interface: a study on the formation of cured mortar structure in masonry using NMR, PFM and XRD. Heron, 44, 257-270.

Dalmay, P., Smith, A., Chotard, T., Sahay-Turner, P., Gloaguen, V., \& Krausz, P. (2010). Properties of cellulosic fibre reinforced plaster: influence of hemp or flax fibres on the properties of set gypsum. Journal of Material Science, 45, 793-803. http://dx.doi.org/10.1007/s10853-009-4002-x

de Silva, P. S., \& Glasser, F.P. (1993). Phase relations in the system CaO-Al2O3-SiO2-H2O relevant to metakaolin - calcium hydroxide hydration. Cement and Concrete Research, 23, 627-639. http://dx.doi.org/10.1016/0008-8846(93)90014-Z

Donchev, I., Nivov, J., Doykov, I., Petrova, N., \& Dimova, L. (2010). On the formation of cement phases in the course of the interaction of kaolinite with $\mathrm{CH}$. Journal of the University of Chemical Technology and Metallurgy, 45, 391-396.

EN 196-1 Methods of testing cement. Determination of strength. (2010). European Committee for Standardisation CEN, Brussels.

EN 459-2 Building lime, part 2: Test Methods. (2010). European Committee for Standardisation CEN, Brussels.

EN 459-Building lime. Part 1: Definitions, specifications and conforming criteria. (2010). European Committee for Standardisation CEN, Brussels. 
Fang, Y., Al-Assaf, S., Phillips, G., Nishinari, K., Funami, T., \& Williams, P. (2008). Binding behavior of calcium to polyuronates: Comparison of pectin with alginate. Carbohydrate Polymers, 72, 334-341. http://dx.doi.org/10.1016/j.carbpol.2007.08.021

Goodwin, J. F., \& West, W. H. (1982). A Review of the Literature on Brick/Mortar Bond. Proceedings of the British Ceramic Society, 30, 23-37.

Govin, A., Peschard, A., \& Guyonnet, R. (2006). Modification of cement hydration at early ages by natural and heated wood. Cement and Concrete Composites, 28, 12-20. http://dx.doi.org/10.1016/j.cemconcomp. 2005.09.002

He, C., Makovicky, E., \& Osbæck, B. (1994). Thermal stability and pozzolanic activity of calcined kaolin. Applied Clay Science, 9, 165-187. http://dx.doi.org/10.1016/0169-1317(94)90018-3

Kavasa, T., Olgunb, A., Erdoganb, Y., \& Oncec G. (2007). The effect of pectin on the physicochemical and mechanical properties of cement containing boron. Building and Environment, 42, 1803-1809. http://dx.doi.org/10.1016/j.buildenv.2006.01.018

Massazza, F. (2007). Pozzolana and pozzolanic cements. In P. C. Hewlett (Ed.), Lea's chemistry of cement and concrete (pp. 471-602). UK: Elsevier.

Murat, M. (1983). Hydration reaction and hardening of calcined clays and related minerals. I. Preliminary investigation on metakaolinite. Cement and Concrete Research, 13, 259-266. http://dx.doi.org/10.1016/0008-8846(83)90109-6

Peschard, A., Govin, A., Grosseau, P., Guilhot, B., \& Guyonnet, R. (2004). Effect of polysaccharides on the hydration of cement paste at early ages. Cement and Concrete Research, 34, 2153-2158. http://dx.doi.org/10.1016/j.cemconres.2004.04.001

Ramachandran, V. S., Feldman, R. F, \& Beaudoin, J. J. (1981). Concrete Science. London: Heyden \& Son Ltd.

Reda Taha, M. M., \& Shrive, N. G. (2001). The use of pozzolans to improve bond and bond strength. Proceedings of the 9th Canadian Masonry Symposium. University of New Brunswick. Canada.

Renard, C., \& Thibault, J. F. (1996). Degradation of pectins in alkaline conditions: kinetics of demethylation. Carbohydrate Research, 286, 139-150. http://dx.doi.org/10.1016/0008-6215(96)00056-0

Rojas, M. F., \& Cabrera, J. (2002). The effect of temperature on the hydration rate an d stability of the hydration phases of metakaolin-lime-water systems. Cement and Concrete Research, 32, 133-138. http://dx.doi.org/ 10.1016/S0008-8846(01)00642-1

Savastano, Jr H., \& Agopyan, V. (1999). Transition zone studies of vegetable fibre-cement paste composites. Cement and Concrete Composites, 21, 49-57. http://dx.doi.org/10.1016/S0958-9465(98)00038-9

Sedan, D., Pagnoux, C., Chotard, T., Smith, A., Lejolly, D., Gloaguen, V., \& Krausz, P. (2007). Effect of calcium rich and alkaline solutions on the chemical behaviour of hemp fibres. Journal of Material Science, 42, 9336-9342. http://dx.doi.org/10.1007/s10853-007-1903-4

Walker, R., \& Pavía, S. (2010). Behaviour and properties of lime- pozzolan pastes. In W. Jäger, B. Haseltine, \& A. Fried (Eds.), 8th International Masonry Conference (pp. 353-362). Dresden.

Walker, R., \& Pavía, S. (2011). Physical properties and reactivity of pozzolans, and their influence on the properties of lime-pozzolan pastes. Materials and Structures, 44, 1139-1150. http://dx.doi.org/10.1617/s11527-010-9689-2

Young, J. (1972). A review of the mechanisms of set-retardation in portland cement pastes containing organic admixtures. Cement and Concrete Research, 2, 415-433. http://dx.doi.org/10.1016/0008-8846(72)90057-9

Zsivanovits, G., MacDougall, A., Smith, A., \& Ring, S. (2004). Material properties of concentrated pectin networks. Carbohydrate Research, 339, 1317-1322. http://dx.doi.org/10.1016/j.carres.2004.02.027

\section{Copyrights}

Copyright for this article is retained by the author(s), with first publication rights granted to the journal.

This is an open-access article distributed under the terms and conditions of the Creative Commons Attribution license (http://creativecommons.org/licenses/by/3.0/). 